\section{(2) OPEN ACCESS}

\title{
Increase of a wide range of bioactive substances in an active phase of neuro-Sweet disease
}

\author{
Hiroi Kusaka, Katsuya Nagatani (D) , Takeo Sato, Seiji Minota
}

Division of Rheumatology and Clinical Immunology, Jichi Medical University, Simotsuke, Tochigi, Japan

\section{Correspondence to Dr Katsuya Nagatani; knagatani@jichi.ac.jp}

Accepted 17 March 2020

Check for updates

(c) BMJ Publishing Group Limited 2020. Re-use permitted under CC BY-NC. No commercial re-use. See rights and permissions. Published by BMJ.

To cite: Kusaka $\mathrm{H}$ Nagatani K, Sato T, et al. BMJ Case Rep 2020;13:e233457. doi:10.1136/bcr-2019233457

\section{SUMMARY}

We present the case of a patient whose skin findings and human leucocyte antigen (HLA) typing were key findings for the diagnosis of his neuro-Sweet disease. A 55-year-old Japanese man with skin rashes and high fever suddenly developed consciousness disturbance, and brain MRI showed encephalitis and leptomeningitis. Neuro-Behçet disease or microbial infection was initially suspected, but he was eventually diagnosed with neuroSweet disease based on his skin rashes and pathology and the presence of HLA-B54 and Cw1. He responded to glucocorticoid and recovered without neurological sequelae. The involvement of cytokines has been implicated in the pathogenesis of Sweet disease, but the number of cytokines assayed in each case report is limited. In our patient's case, the result of a 27-cytokine assay showed increases in a wide range of bioactive substances including inflammatory cytokines, growth factors and chemoattractants in the active phase, indicating the involvement of multiple cytokines in the pathogenesis of Sweet disease.

\section{BACKGROUND}

Sweet disease, first described by Robert Sweet in 1964 as acute febrile neutrophilic dermatosis, is a non-infectious disease characterised by fever, leucocytosis and painful oedematous plaques. ${ }^{1}$ Conjunctivitis, myalgia, arthralgia and oral lesions occur in some patients with this syndrome. ${ }^{2}$ The skin pathology of Sweet disease shows massive neutrophil infiltration in the dermis without vasculitis or thrombosis. The increased chemotaxis of neutrophils and cytokines is believed to play a central role in the disease pathogenesis, ${ }^{13}$ but the precise pathogenesis of Sweet disease remains to be elucidated.

Sweet disease occasionally affects the central nervous system and presents with encephalitis and meningitis. ${ }^{4}$ Sweet disease with neurological symptoms was first reported in 1983 by Chiba, ${ }^{5}$ and in 1999, Hisanaga et al proposed the concept of neuro-Sweet disease (NSD). ${ }^{6}$ The characteristics of patients with NSD and those with neuro-Behçet disease (NBD) are sometimes quite similar, and there is a concept of neuroneutrophilic disease that encompasses both NSD and NBD. ${ }^{7}$ It is clinically important to discriminate NSD from NBD because of their different responses to glucocorticoid treatment and differing neurological prognoses.

Here, we describe the case of a patient with NSD who showed neurological symptoms and brain imaging findings similar to those of NBD. NSD was diagnosed on the basis of the patient's skin pathology and human leucocyte antigen (HLA) typing. There have been reports of cytokine analyses in Sweet disease, but the number of cytokines assayed in each case report of NSD is limited. In our patient's case, 27 cytokines were assayed, and the levels of 14 bioactive substances were increased in an active phase of disease. The analyses of multiple cytokines in a patient suspected of having Sweet disease may therefore help elucidate the pathogenesis and develop cytokine-targeted treatments.

\section{CASE PRESENTATION}

A 55 -year-old Japanese man presented with a painful ulcer of the tongue 3 weeks before admission. His past illness and family history were unremarkable. His left eye was congested due to dendritic keratitis, which improved with a topical steroid. $\mathrm{He}$ showed no findings of uveitis. One week before his admission, furred tongue and glossalgia developed, and he had difficulty eating. He took an antifungal agent due to a suspicion of candida stomatitis, but the medication had no effect. Two days before admission, he developed a fever of $38^{\circ} \mathrm{C}$ and painful skin rashes on his trunk and limbs, which did not respond to antimicrobials. He had joint pain in his elbow and shoulder.

He visited an emergency room because eating and drinking were difficult for him due to high fever and mouth pain. He was hospitalised with a suspicion of viral infection such as hand-foot-andmouth disease and received fluid replacement and treatment with a non-steroidal anti-inflammatory drug; however, he showed no improvement, and at 1 week after admission, he developed drowsiness. The next day, his consciousness disturbance has progressed, and he was unable to speak. His body temperature rose to $39.4^{\circ} \mathrm{C}$, and his Glasgow Coma Scale Score was E1V2M4. Many oral ulcers and glossitis were observed. He had soft lymph node swelling $(1 \mathrm{~cm}$ diameter) in his neck. Elevated erythematous plaques with crusts were present on his left forearm (figure 1), on the back of his left hand, and on his right toe. Mild paresis was observed in his left upper and lower limbs; there were no pathological reflexes. Acyclovir was started at $1800 \mathrm{mg} /$ day empirically with a suspicion of herpes encephalitis, but there was no response to acyclovir. 


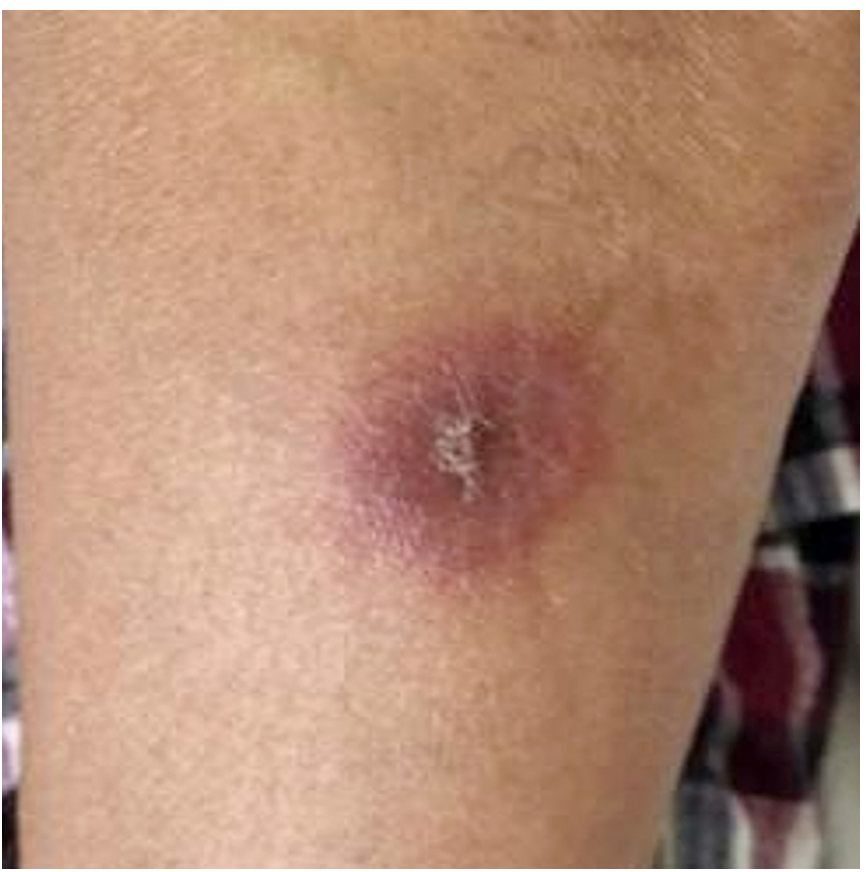

Figure 1 Oedematous erythematous plaques with crusts on the patient's left forearm.

\section{INVESTIGATIONS}

At the onset of the patient's consciousness disturbance, his white cell count (WCC) was $10.4 \times 10^{9} / \mathrm{L}$ with $86 \%$ neutrophils. The serum level of C-reactive protein (CRP) was $16.2 \mathrm{mg} / \mathrm{dL}$. The results of other haematological and biochemical tests were grossly normal. Bacterial blood cultures and specific autoantibodies were all negative. A cerebrospinal fluid analysis showed only mild increases in protein and cells, and negative results were obtained by a bacterial culture and qualitative PCR for herpes simplex-1, herpes simplex-2, varicella zoster virus, cytomegalovirus, human herpes virus- 6 and Epstein-Barr virus. In fluidattenuated inversion recovery (FLAIR) images of brain MRI, there were high-intensity signals in the right basal ganglia, subcortical white matter and leptomeningeal gadolinium enhancement (figure 2A-D). The HLA typing revealed HLA-A11, HLA-A24, HLA-B54, HLA-B60, HLA-Cw1 and HLA-Cw4. Skin pathology from the patient's forearm showed massive neutrophil infiltration in the dermis without vasculitis or thrombosis (figure 3).

\section{DIFFERENTIAL DIAGNOSIS}

As differential diagnoses, we considered acute NBD, viral or bacterial infection in the central nervous system, and NSD. We

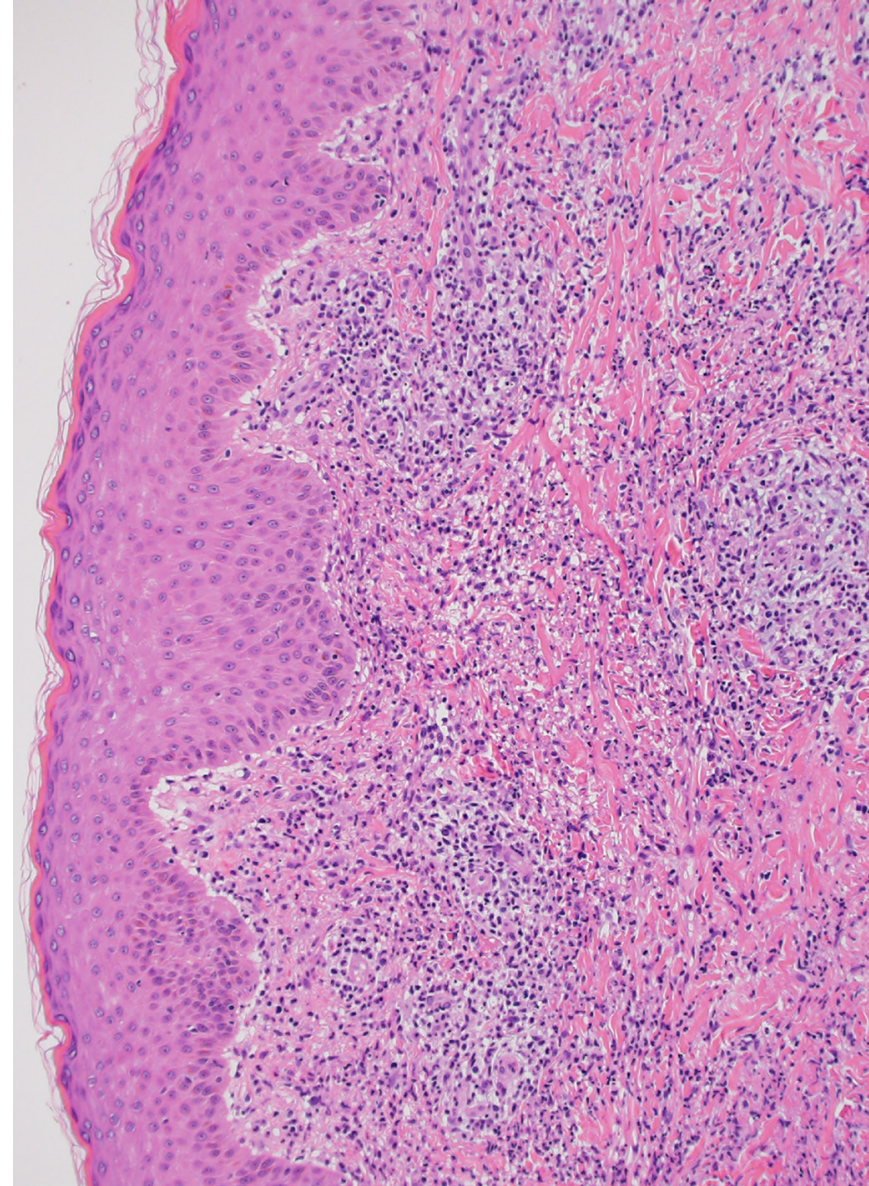

Figure 3 Skin pathology showing a massive infiltration of neutrophils in the dermis. H\&E staining; original magnification 100x.

performed several examinations to differentiate these diseases. The patient lacked HLA-B51 (which is typical for Behçet disease), but he had HLA-B54 and HLA-Cw1, which are frequently associated with Sweet disease, especially with neurological involvement. We considered that bacterial and herpes infections could be denied because the results of bacterial cultures and a viral test for herpes simplex in cerebrospinal fluid were negative and the patient did not respond to antimicrobials or acyclovir. The pssatient's findings of painful oedematous plaques and neutrophil infiltration in the dermis without vasculitis and thrombosis were compatible with those of Sweet disease. In addition, the patient responded to prednisolone as described in the Treatment
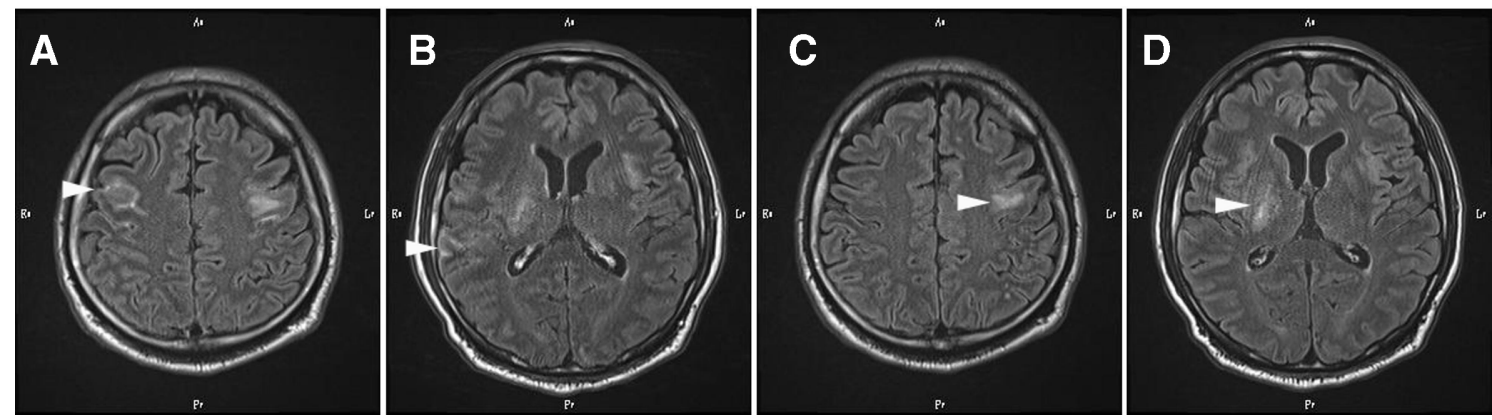

Figure 2 (A, B) Brain MRI showing high signal intensities in the right basal ganglia and left subcortical white matter in fluid-attenuated inversion recovery (FLAIR; arrowheads). (C, D) Gadolinium-enhanced FLAIR showing leptomeningeal contrast enhancement (arrowheads). 
Box 1 Summary of the patient's findings that met the criteria for neuro-Sweet disease

1. Neurological features: glucocorticoid-responsive encephalitis and meningitis accompanied by fever $>38^{\circ} \mathrm{C}$.

2. Dermatological features: painful erythematous plaques. Neutrophilic infiltration of the dermis, and the absence of leucocytoclastic vasculitis.

3. Other features: absence of cutaneous vasculitis and thrombosis. Absence of typical uveitis.

4. Human leucocyte antigen (HLA) associations: HLA-Cw1 or B54 positive. HLA-B51 negative.

section. On the basis of these findings, we diagnosed NSD based on the NSD criteria proposed by Hisanaga et al (box 1). ${ }^{4}$

\section{TREATMENT}

On the second day after the patient developed drowsiness, we initiated treatment with $1000 \mathrm{mg} /$ day of methylprednisolone for 3 days. His fever was resolved within the first day. The following day, the patient's skin rashes and mouth pain had improved, and he was able to converse with medical staff and his family. The methylprednisolone pulse was followed by $60 \mathrm{mg}(1 \mathrm{mg} / \mathrm{kg})$ of prednisolone per day, and the patient's CRP level and the WCC returned to normal levels in 2 weeks. He then continued to take $60 \mathrm{mg}$ of prednisolone per day for 2 weeks, and then the prednisolone was tapered to $50 \mathrm{mg} /$ day. During this treatment course, the patient developed aspiration pneumonia due to consciousness disturbance; this was treated with intravenous antibiotics for 5 days. The patient had temporarily mild steroid-induced insomnia and impaired glucose intolerance, but these adverse events were manageable with medication.

\section{OUTCOME AND FOLLOW-UP}

The patient underwent physical therapy for dysphagia and was discharged 3 weeks after starting steroid treatment, with no neurological sequelae. During the first 2 months after discharge, colchicine was added as a steroid-sparing agent. The patient returned to his job at 3 months post discharge. The prednisolone was gradually tapered over 1 year to $7 \mathrm{mg} /$ day, and he had no signs of relapse. His physical functioning returned to the normal level.

To investigate the role of cytokines in the pathogenesis of Sweet disease, we compared the levels of 27 cytokines in the patient's serum at the onset of his neurological symptoms with those in remission at 8 months after treatment, with the BioPlex Pro Human Cytokine 27-plex Assay (Bio-Rad Laboratories, Hercules, California, USA). As shown in table 1, the levels of 14 bioactive substances including inflammatory cytokines, growth factors and chemoattractants were increased at the onset of neurological symptoms and returned to the normal levels at remission. In contrast, helper $\mathrm{T}$ cell-specific cytokines that are representative of acquired immunity were not detectable at the onset of neurological symptoms.

\section{DISCUSSION}

In our patient's case, the differential diagnosis suspected first was NBD because of his oral ulcers, skin rashes, encephalitis and leptomeningitis. However, he lacked typical features of Behçet disease; the HLA typing showed the presence of HLAB54 and HLA-Cw1 and the absence of HLA-B51, findings which suggested that Sweet disease was more likely than Behçet disease. ${ }^{48}$ In contrast to the dermatological features of Behçet disease, our patient's skin findings showed painful oedematous plaques and neutrophil infiltration in the dermis without vasculitis or thrombosis, which are distinctive to Sweet disease. Although there is some controversy regarding the differences between Sweet disease and Behçet disease, we eventually diagnosed the patient as having NSD based on its criteria. ${ }^{4}$

The aetiology of Sweet disease is heterogeneous because of a wide variety of underlying diseases including infections, autoimmune diseases, haematological diseases, malignancies, inflammatory bowel diseases, pregnancy and drug use. In our patient's case, no definite underlying diseases were revealed by our examinations. It has been suggested that Sweet disease is attributable to a hypersensitive reaction or to an autoinflammatory disease. ${ }^{9} 10$

\begin{tabular}{|c|c|c|c|c|c|c|c|}
\hline Cytokine (pg/mL) & LLQ & Before treatment* & At remissiont & Cytokine (pg/mL) & LLQ & Before treatment* & At remissiont \\
\hline IL-1 $\beta$ & 0.6 & 5.0 & ND & Eotaxin & 0.1 & 67.1 & 97.8 \\
\hline IL-2 & 2.1 & ND & ND & G-CSF & 6.0 & 63.1 & ND \\
\hline IL-4 & 1.1 & ND & ND & GM-CSF & 0.4 & ND & ND \\
\hline IL-5 & 0.1 & 5.5 & ND & IFN- $\gamma$ & 0.3 & ND & ND \\
\hline IL-8 & 1.0 & 17.8 & 2.7 & MIP-1 $\alpha$ & 0.04 & 2.3 & ND \\
\hline IL-9 & 2.3 & 9.3 & 3.1 & PDGF & 4.6 & 10537 & 2006 \\
\hline IL-10 & 1.7 & ND & ND & MIP-1 $\beta$ & 0.5 & 86.8 & 61.0 \\
\hline IL-12 (p70) & 1.1 & ND & ND & RANTES & 3.7 & 4014.3 & 3265.0 \\
\hline IL-13 & 0.3 & ND & ND & TNF- $\alpha$ & 3.2 & 32.3 & 9.3 \\
\hline
\end{tabular}

*At the onset of neurological symptoms.

tAt the remission phase after 8 months with glucocorticoid treatment.

FGF, fibroblast growth factor; G-CSF, granulocyte colony-stimulating factor; GM-CSF, granulocyte macrophage colony-stimulating factor; IFN, interferon; IL, interleukin; IP, interferon-inducible protein; LLQ, lower limit of quantification; MCP, monocyte chemotactic protein; MIP, macrophage inflammatory protein; ND, not determined; PDGF, platelet-derived growth factor; ra, receptor antagonist; RANTES, regulated on activation normal T-cell expressed and secreted; TNF, tumour necrosis factor; VEGF, vascular endothelial growth factor. 
Cytokines are thought to play important roles in the pathogenesis of Sweet disease. For example, the administration of granulocyte colony-stimulating factor (G-CSF), granulocyte macrophage colony-stimulating factor (GM-CSF), interleukin (IL)- 1 or interferon (IFN)- $\gamma$ triggers Sweet disease. ${ }^{11-14}$ The levels of endogenous cytokines such as G-CSF, IL-1, IL-2, IL-6, IL-8, IL-17, IFN- $\gamma$ and tumour necrosis factor (TNF)- $\alpha$ are increased in Sweet disease. ${ }^{615-19}$ There is also a predominance of T-helper 1-type cytokines in Sweet disease, ${ }^{2021}$ indicating an involvement of acquired immunity. Both cytokine therapy and anticytokine therapy have been reported to be effective for Sweet disease. ${ }^{22-24}$

However, the number of the cytokines assayed and reported to date is very limited, and the overall involvement of cytokines in Sweet disease thus remains to be elucidated. In our patient's case, in order to determine the comprehensive cytokine kinetics at the highest level of disease activity and in remission, we assayed the serum levels of 27 cytokines simultaneously. Among the cytokines assayed, the patient's levels of inflammatory cytokines (IL-1 $1 \beta$, IL-1ra, IL-6 and TNF- $\alpha$ ), chemoattractants (IL-8, IP-10 and macrophage inflammatory protein $1 \alpha$ ) and growth factors (fibroblast growth factor, G-CSF, platelet-derived growth factor and vascular endothelial growth factor) were increased. The patterns of the cytokine profile were partly consistent with those of previous reports, but there was no T-helper 1 cytokine predominance in our patient's case. The cytokine profiles may

\section{Patient's perspective}

When I got sick, I was in a hazy state and I could not eat. I had no idea of the cause. I was unconscious for two days, but I remember that I was ordered to move to the MRI table. When my consciousness was restored, I saw my wife was crying. And then, my consciousness got clear like fog clears. For several days, I could not eat because I had difficulty in swallowing, and I felt frustrated about that. I also felt that my muscle strength had weakened. I didn't know Behçet disease and Sweet disease, but I had no anxiety because doctors explained my disease and I could understand very well. After discharge, to recover my muscle strength and resistance to disease, I have been doing horse riding which is my favorite sport.

\section{Learning points}

- Sweet disease is a rare inflammatory skin disease characterised by fever, leucocytosis and distinctive skin rashes. Neuro-Sweet disease should be considered as one of the differential diagnoses when physicians encounter a patient with skin rashes and encephalitis or meningitis.

- Sweet disease and Behçet disease share similar clinical manifestations. Neuro-Sweet disease can mimic neuro-Behçet disease and cannot be differentiated based on neurological symptoms alone. Human leucocyte antigen typing results and skin findings are the major differences between these diseases, but controversies remain regarding these differences.

- Multiple cytokines appear to be involved in the active phase of Sweet disease. The cytokine profiles in Sweet disease may be non-specific, but the accumulation of cytokine profiles in Sweet disease will help elucidate the pathogenesis of Sweet disease and lead to cytokine-targeted therapies tailored to individual patients with refractory or recurrent Sweet disease. differ from patient to patient because the aetiology of Sweet disease is heterogeneous and may be non-specific. However, the analysis of cytokines in Sweet disease may help elucidate the pathogenesis and develop cytokine-targeted therapies tailored to individual patients with refractory or recurrent Sweet disease. Biologics that target inflammatory cytokines, chemoattractants or growth factors or JAK inhibitors that target intracellular signal transductions involved in multiple cytokines may be effective treatments for Sweet disease. This point is intriguing and should be addressed in future investigations.

A wide variety of neurological symptoms of NSD have been reported, including consciousness disorder, headache and paresis. ${ }^{25}$ Asians account for a majority of the patients with NSD, as 56 of the 69 cases reported worldwide have been from Asia, in particular in Japan. ${ }^{25}$ Neurological involvement usually follows skin lesions, but it can also be an initial manifestation of NSD. ${ }^{26}$ The development of neurological symptoms in our patient's case was rapid compared with past reports. ${ }^{27}{ }^{28} \mathrm{NSD}$ can mimic NBD, and it appears that NSD cannot be differentiated from NBD by neurological symptoms alone.

Radiological and pathological studies have shown that the basal ganglia, thalamus, brainstem, subcortical white matter and pia mater are the sites of neurological involvement in NSD. ${ }^{425} 2930$ MRI including FLAIR and gadolinium-enhanced FLAIR are essential for the detection of encephalitis and leptomeningitis, ${ }^{31}$ but it does not seem possible to discriminate NSD and NBD based solely on the MRI findings.

There are differences between NSD and NBD in their response to glucocorticoid treatment and in the neurological prognosis. Patients with NSD usually respond well to a glucocorticoid and show little neurological sequelae. ${ }^{4} 6$ There are two types of neurological involvement in NBD: acute NBD and chronic progressive NBD. Chronic progressive NBD is resistant to glucocorticoid treatment, and the clinical course is often progressive and occasionally lethal. ${ }^{32}$ Because of these differences, it is clinically important to differentiate NSD and NBD. Vasculitis in NBD may account for the worse prognosis.

In conclusion, clinicians must keep NSD in mind in cases of unexplained meningoencephalitis and skin eruptions. NSD can mimic NBD, and it is sometimes difficult to differentiate NSD from NBD; pathological findings of the skin lesions and HLA typing may have additive value for the differentiation. An accumulation of cytokine profiles in Sweet disease is definitely needed to improve our understanding of the pathophysiology and to pursue possible molecular targeted therapies.

Acknowledgements The authors thank Dr Yu Yamamoto, Dr Masami Matsumura and Dr Masahiro Iwamoto for invaluable suggestions, and Dr Natsuki Shima, Ms Chiyomi Hayashi and Ms Sachiko Mamada for excellent technical help.

Contributors HK provided care for the patient and drafted the manuscript. KN and TS contributed to the conception and design of the manuscript. KN contributed to acquisition and analysis of the data. TS and SM revised the manuscript critically for important intellectual content. All authors approved the final version.

Funding The authors have not declared a specific grant for this research from any funding agency in the public, commercial or not-for-profit sectors.

Competing interests None declared.

\section{Patient consent for publication Obtained}

Provenance and peer review Not commissioned; externally peer reviewed.

Open access This is an open access article distributed in accordance with the Creative Commons Attribution Non Commercial (CC BY-NC 4.0) license, which permits others to distribute, remix, adapt, build upon this work non-commercially, and license their derivative works on different terms, provided the original work is properly cited and the use is non-commercial. See: http://creativecommons.org/ licenses/by-nc/4.0/. 


\section{ORCID iD}

Katsuya Nagatani http://orcid.org/0000-0002-2877-189X

\section{REFERENCES}

1 Sweet RD. An acute febrile neutrophilic dermatosis. Br J Dermatol 1964;76:349-56.

2 Cohen PR. Sweet's syndrome--a comprehensive review of an acute febrile neutrophilic dermatosis. Orphanet J Rare Dis 2007;2:34.

3 Reuss-Borst MA, Pawelec G, Saal JG, et al. Sweet's syndrome associated with myelodysplasia: possible role of cytokines in the pathogenesis of the disease. $\mathrm{Br}$ J Haematol 1993;84:356-8.

4 Hisanaga K, Iwasaki Y, Itoyama Y, et al. Neuro-Sweet disease: clinical manifestations and criteria for diagnosis. Neurology 2005;64:1756-61.

5 Chiba S. Sweet's syndrome with neurologic signs and psychiatric symptoms. Arch Neurol 1983;40:829.

6 Hisanaga K, Hosokawa M, Sato N, et al. "Neuro-sweet disease" : benign recurrent encephalitis with neutrophilic dermatosis. Arch Neurol 1999:56:1010-3.

7 Hisanaga K. Neuro-neutrophilic disease: neuro-Behçet disease and neuro-Sweet disease. Intern Med 2007;46:153-4.

8 Mizoguchi M, Matsuki K, Mochizuki M, et al. Human leukocyte antigen in sweet's syndrome and its relationship to Behçet's disease. Arch Dermatol 1988;124:1069-73.

9 Petrozzi JW, Warthan TL. Sweet's syndrome: unique local response to streptococcal antigen. Cutis 1976;17:267-72.

10 Jo T, Horio K, Migita K. Sweet's syndrome in patients with MDS and MEFV mutations. N Engl J Med 2015;372:686-8.

11 Bidyasar S, Montoya M, Suleman K, et al. Sweet syndrome associated with granulocyte colony-stimulating factor. J Clin Oncol 2008;26:4355-6.

12 Kim YJ, Lee HY, Lee JY, et al. Interferon beta-1b-induced sweet's syndrome in a patient with multiple sclerosis. Int J Dermatol 2015;54:456-8.

13 Rodriguez-Lojo R, Castiñeiras I, Juarez Y, et al. Sweet syndrome associated with interferon. Dermatol Online J 2014:21:18.

14 Kumar G, Bernstein JM, Waibel JS, et al. Sweet's syndrome associated with sargramostim (granulocyte-macrophage colony stimulating factor) treatment. Am J Hematol 2004;76:283-5.

15 Kawakami T, Ohashi S, Kawa Y, et al. Elevated serum granulocyte colony-stimulating factor levels in patients with active phase of sweet syndrome and patients with active Behcet disease: implication in neutrophil apoptosis dysfunction. Arch Dermatol 2004;140:570-4.

16 Takano Y, Fujino H, Yachie A, et al. Serum cytokine profile in pediatric sweet's syndrome: a case report. J Med Case Rep 2017;11:178.
17 Marzano AV, Fanoni D, Antiga E, et al. Expression of cytokines, chemokines and other effector molecules in two prototypic autoinflammatory skin diseases, pyoderma gangrenosum and sweet's syndrome. Clin Exp Immunol 2014;178:48-56.

18 Arun B, Berberian B, Azumi N, et al. Sweet's syndrome during treatment with alltrans retinoic acid in a patient with acute promyelocytic leukemia. Leuk Lymphoma 1998;31:613-5.

19 Marzano AV, Cugno M, Trevisan V, et al. Inflammatory cells, cytokines and matrix metalloproteinases in amicrobial pustulosis of the folds and other neutrophilic dermatoses. Int J Immunopathol Pharmacol 2011;24:451-60.

20 Giasuddin AS, El-Orfi AH, Ziu MM, et al. Sweet's syndrome: is the pathogenesis mediated by helper T cell type 1 cytokines? J Am Acad Dermatol 1998;39:940-3.

21 Kimura A, Sakurai T, Koumura A, et al. Longitudinal analysis of cytokines and chemokines in the cerebrospinal fluid of a patient with neuro-Sweet disease presenting with recurrent encephalomeningitis. Intern Med 2008;47:135-41.

22 Ambrose NL, Tobin AM, Howard D. Etanercept treatment in sweet's syndrome with inflammatory arthritis. J Rheumatol 2009;36:1348.2-9.

23 Kluger N, Gil-Bistes D, Guillot B, et al. Efficacy of anti-interleukin-1 receptor antagonist anakinra (Kineret $\left.{ }^{\circledR}\right)$ in a case of refractory sweet's syndrome. Dermatology 2011:222:123-7.

24 Rahier JF, Lion L, Dewit O, et al. Regression of sweet's syndrome associated with Crohn's disease after anti-tumour necrosis factor therapy. Acta Gastroenterol Belg 2005;68:376-9.

25 Drago F, Ciccarese G, Agnoletti AF, et al. Neuro sweet syndrome: a systematic review. A rare complication of sweet syndrome. Acta Neurol Belg 2017;117:33-42.

26 Makimoto G, Manabe Y, Yamakawa C, et al. Two cases of possible neuro-Sweet disease with meningoencephalitis as the initial manifestation. Neurol Int 2012;4:e5.

27 Kitamura S, Hamauchi A, Ota M. Neuro-Sweet's disease.. Int J Dermatol 2016:55:e513-4.

28 Song I-U, Kim J-S, Kim Y-I, et al. Sweet's syndrome associated with acute-onset encephalitis. Eur Neurol 2007;57:182-4.

29 Fukushima K, Hineno A, Kodaira M, et al. Reversible extensive leukoencephalopathy in sweet disease: a case report. J Neurol Sci 2008;275:178-80.

30 Kokubo Y, Kuzuhara S, Isoda K, et al. Neuro-Sweet disease: report of the first autopsy case. J Neurol Neurosurg Psychiatry 2007;78:997-1000.

31 Fukuoka H, Hirai T, Okuda T, et al. Comparison of the added value of contrastenhanced 3D fluid-attenuated inversion recovery and magnetization-prepared rapid acquisition of gradient echo sequences in relation to conventional postcontrast T1-weighted images for the evaluation of leptomeningeal diseases at 3T. AJNR Am J Neuroradiol 2010;31:868-73.

32 Hirohata S, Kikuchi H, Sawada T, et al. Clinical characteristics of neuroBehcet's disease in Japan: a multicenter retrospective analysis. Mod Rheumatol 2012;22:405-13.

Copyright 2020 BMJ Publishing Group. All rights reserved. For permission to reuse any of this content visit https://www.bmj.com/company/products-services/rights-and-licensing/permissions/ BMJ Case Report Fellows may re-use this article for personal use and teaching without any further permission.

Become a Fellow of BMJ Case Reports today and you can:

- Submit as many cases as you like

- Enjoy fast sympathetic peer review and rapid publication of accepted articles

- Access all the published articles

Re-use any of the published material for personal use and teaching without further permission

Customer Service

If you have any further queries about your subscription, please contact our customer services team on +44 (0) 2071111105 or via email at support@bmj.com.

Visit casereports.bmj.com for more articles like this and to become a Fellow 